\title{
AMLODIPINE INTOXICATION: A DIFFERENT PRESENTATION OF OVERDOSE OF A COMMONLY PRESCRIBED ANTI-HYPERTENSIVE
}

\author{
B.R. Shivakumar ${ }^{1}$, Hareesh R², Akshay Agte ${ }^{3}$
}

\section{HOW TO CITE THIS ARTICLE:}

B.R. Shivakumar, Hareesh R, Akshay Agte. "Amlodipine Intoxication: A different presentation of overdose of a commonly prescribed Anti-Hypertensive". Journal of Evolution of Medical and Dental Sciences 2013; Vol. 2, Issue 50, December 16; Page: 9801-9805.

ABSTRACT: Calcium channel blockers (CCBs) are one of the most commonly prescribed antihypertensive medications in India due to good efficacy and cost-effectiveness. Overdose of this wonderful dihydropyridine though common in the western world has been scarcely reported in the Indian literature. We report the case of intoxication with Amlodipine, in a young female software technician. The patient came with a very different presentation of loose stools with severe hypotension, bradycardia, altered sensorium, hyperglycemia, respiratory distress and metabolic acidosis. With the patient on assisted mechanical ventilation and without any correlating history, there was a diagnostic dilemma. But with detailed history taking and from repeated conversations with the relatives, empty strips of Amlodipine tablets were found at the patient's bedside. The patient was treated with stomach wash, fluid resucsitation, calcium gluconate, Dopamine, hyperinsulinemia euglycemia therapy. The patient made a complete recovery and was discharged after a psychiatric consultation.

KEY WORDS: Amlodipine, Loose stools, Calcium gluconate, Hyperinsulinemia euglycemia therapy.

INTRODUCTION: Amlodipine is one of the most frequently prescribed anti hypertensives in the Indian scenario, where cheap and effective medications are required to ensure compliance. Overdose of this wonderful dihydropyridine though common in the western world has been scarcely reported in the Indian literature.

Calcium channel blockers (CCB) are the leading cause of overdose death among all cardiovascular medicines ${ }^{1}$. Secondary to overdose, Amlodipine is known to cause shock. The hemodynamic shock is likely caused by calcium channel blockade in myocardial smooth muscle and pancreatic beta cells. This blockade leads to peripheral vasodilatation, hyperglycemia, hypoinsulinemia, metabolic acidosis and shock ${ }^{2}$

CASE REPORT: A 27 yr old female software technician, resident of Bangalore, Karnataka was brought to Casualty in altered sensorium with a history of vomiting and watery loose stools since 3 days, associated with decreased urine output and worsening breathlessness since 2 days.

On examination patient was semiconscious with a GCS of 10/15 (E2 V3 M5). She was dehydrated with cold clammy extremities and had central cyanosis along with bilateral pitting pedal edema extending up-to mid half of leg and facial puffiness. Pulse was 100/min, low volume and B.P:80/60 mm Hg. Patient was tachypnoeic with a respiratory rate of $28 / \mathrm{min}$ and Spo 2 of $80 \%$ with $6 \mathrm{~L}$ of 02 .Respiratory system examination revealed stony dull note on percussion and absent breath sounds on auscultation were noted in in B/l Infra-scapular \& Infra-axillary areas. Per abdomen examination revealed distension with shifting dullness. 
Complete blood count was unremarkable except for an E.S.R of $95 \mathrm{~mm}$ in $1 \mathrm{st} \mathrm{hr}$. Urine analysis was normal. Serum Creatinine was $2.8 \mathrm{mg} / \mathrm{dl}$, Blood Urea - $52 \mathrm{mg} / \mathrm{dl}$, RBS - $214 \mathrm{mg} / \mathrm{dl}$. Serum Electrolytes were normal. Stool routine, hanging drop was negative and stool culture sensitivity was sent. LFT, serum amylase and lipase were normal.TSH was $0.38 \mathrm{uIU} / \mathrm{ml}$.

ECG showed Left axis deviation with First degree Heart Block. [PR interval - 0.28]

Provisional diagnosis of Acute Gastroenteritis with hypovolemic shock in acute renal failure and first degree heart block was made and managed accordingly.

On Day 2 she was electively intubated and put on inotropic support in view of dropping SPo2 and hypotension along with deteriorating sensorium. Patient had persistent oliguria and pedal edema had progressed upto the knee. Creatinine showed rising level ( $4 \mathrm{mg} / \mathrm{dl}$ ) with ABG showing metabolic acidosis. (pH- 7.04; PCO2 -34 mmHg;PO2- 89 mmHg; HCO3-08mmol/l). X-ray showed bilateral pleural effusion. USG showed moderate ascites and bilateral pleural effusion. Dialysis as a treatment modality was offered but relatives did not consent. On Day 3, upper limb edema and facial puffiness were apparent. I /0 was $1350 \mathrm{ml} / 200 \mathrm{ml}$, Serum Creatinine - $4.4 \mathrm{mg} / \mathrm{dl}$, 2D Echo normal.

With no improvement in the patient condition and no correlating evidences present, there was a diagnostic dilemma. After repeated conversations with the relatives, empty strips of Amlodipine tablets were found at the patient's bedside at her house.

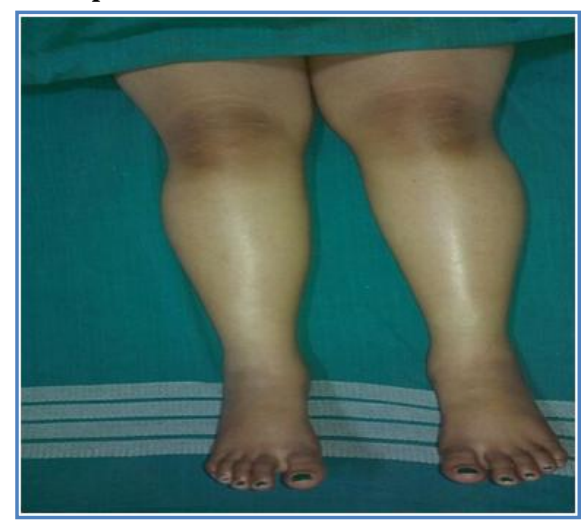

Figure 1: pedal edema on day 2 of admission

We then started treating the patient promptly on the lines of amlodipine poisoning as follows:

S.Calcium - $6 \mathrm{mg} / \mathrm{dl}[9-11]$

S.Magnesium - 1.9meq/1 [1.3- 2.5]

Fasting plasma Insulin level - 22micro units $/ \mathrm{ml}$.

We gave $0.6 \mathrm{ml} / \mathrm{kg}$ bolus of $10 \%$ calcium gluconate over 5-10 min followed by continuous infusion @ $1 \mathrm{ml} / \mathrm{kg} / \mathrm{hr}$, Insulin $0.5 \mathrm{u} / \mathrm{kg} / \mathrm{hr}$ infusion with dextrose started and dopamine continued @ $10 \mathrm{mcg} / \mathrm{kg} / \mathrm{min}$ in addition to nor adrenaline.

On Day 5, patient showed clinical improvement in the form of response to oral commands. Edema had decreased and Urine output improved to $900 \mathrm{ml}$. S. creatinine $(2.2 \mathrm{mg} / \mathrm{dl})$ and S.Calcium $(8.2 \mathrm{mg} / \mathrm{dl})$ began to normalize.

Patient made a steady improvement and was weaned off the ventilator, with normalization of all investigative parameters. Inotropes were gradually tapered and stopped.

Patient was discharged after psychiatric consultation. 


\section{CASE REPORT}

DISCUSSION: Calcium channel blockers are the leading cause of cardiovascular drug overdose and are responsible for $48 \%$ of deaths related to cardiovascular drug exposure. Clinical toxicity of calcium channel blockers usually begins within 30-60 min of ingestion of a dose which is 5-10 times the therapeutic dose.

Treatment of CCB overdose involves gastric decontamination with stomach wash and activated charcoal whereas in slow release (SR) preparations, total gut lavage with polyethylene glycol is recommended.3, 4Hyperinsulinemia-euglycemia (HIE) therapy and calcium gluconate are rapidly becoming mainstay of treatment.

Kenny et al suggest $10 \mathrm{ml}$ of $10 \%$ calcium chloride or $20-30 \mathrm{ml}$ of $10 \%$ calcium gluconate IV and depending on clinical response repeat at every 15-20 minutes up to four doses with monitoring of serum calcium. Continuous calcium infusion of Ca chloride $0.2 \mathrm{ml} / \mathrm{kg} / \mathrm{hr}$ is another option3. Buckley et al.5also discussed the use of calcium to overcome competitive blockade of calcium channels in the cardiac conducting system. The amount of hypercalcemia required to overcome blockade depends on the degree of CCB intoxication 5. Buckley et al. recommended administering one gram of calcium salts every two to three minutes until the cardiac block is reversed on electrocardiogram.

Hyperinsulinemia-euglycemia (HIE) therapy: Insulin increases plasma levels of ionized calcium, improves hyperglycemic acidotic state, improves myocardial utilization of carbohydrates and exerts its own independent inotropic effect. ${ }^{6}$ Insulin infused with dextrose to maintain euglycemia is hence another treatment modality recommended.

Glucagon: Glucagon has both positive inotropic and chronotropic effects as confirmed in multiple animal studies ${ }^{7}$. The principle being that it stimulates adenylcyclase via G proteins, resulting in increased intracellular cyclic AMP which in turn leads to muscle contraction.

The dose recommended is $50-150$ microgram $/ \mathrm{kg}$ given as intravenous bolus. The bolus can be repeated every 3-5 minutes to clinical effect, followed by infusions of the effective dose every hour. Results have not been confirmed in human trials.

Sodium bicarbonate: Treatment of the acidemia may improve the hemodynamic status. If the QRS duration is longer than 120 milliseconds, a 1-2 $\mathrm{mEq} / \mathrm{kg}$ bolus of sodium bicarbonate can be given. ${ }^{7}$

Levosimendan: Levosimendan, a calcium-sensitizing agent indicated for use in patients with acutely decompensated heart failure ${ }^{8}$. Levosimendan sensitizes contractile proteins to calcium by interacting with troponin in cardiac muscle, which prolongs troponin's effect on contractile proteins $^{8}$. Levosimendan also vasodilates via ATP-dependent potassium channels ${ }^{9}$.

Cardiopulmonary bypass: In some cases it allows sufficient time for liver detoxification. ${ }^{10}$

Transvenous pacing: May be required in patients with severe symptomatic bradycardia not responding to Atropine or Isoprenaline infusion. ${ }^{11}$ 
Extracorporeal membrane oxygenation was described in massive Diltiazem overdose for temporary hemodynamic support.12 Therapeutic plasma exchange was also utilized in the management of certain cases of overdose.13

Noncardiogenic pulmonary edema following CCB overdose is well described in the literature.1416Precapillary vasodilatation resulting in excessive pulmonary capillary transudation was suggested as the possible mechanism of non-cardiogenic pulmonary edema by Humbert et al.14

CONCLUSION: Management of poisoning cases is always challenging as the content and quantity of ingested agent can never be truly ascertained. Until a definitive diagnosis is reached keeping an open mind and following strict resuscitative protocols is of paramount importance. Our case more or less proves this statement. It was only after repeated history taking and search of the patient's room, that we were able to come to a diagnosis. The importance of detailed history taking comes again in focus. Hyperinsulinemia-euglycemia (HIE) therapy, calcium gluconate and treatment of shock with ionotropic support remains the mainstay of treatment.

\section{REFERENCES:}

1. Bruce DA, William TB.Overdose causes prolonged calcium channel blocker toxicity. Am J Emerg Med 1998;16:527-8.

2. Vogt S, Mehlig A, Hunziker: Survival of severe intoxicarion due to medical intensive care. Forensic Scilnt;161:216-20, 2006.

3. Kenny J. Treating overdose with calcium channel blockers. BMJ 1994;308:992-3.

4. Buckley NA, Whyte IM, Dawson AH. Overdose with calcium channel blockers. BMJ 1994;308:1639.

5. Buckley NA, Dawson AH, Howarth DM, Whyte IM: Slow release verapamil poisoning. Use of polyethylene glycol whole bowel lavage and high-dose calcium. Med J Aust; 158:202-4, 1993.

6. Patel NP, Pugh ME, Goldberg S, Eiger G. Hyperinsulinemic euglycemia therapy for Verapamil poisoning: A review. Am J Crit Care. 2007;16:498-503.

7. W. Kerns II, "Management of beta-adrenergic blocker and calcium channel antagonist toxicity, "Emergency Medicine Clinics of North America, vol. 25, no. 2, pp. 309-331, 2007.

8. Toller WG, Stranz C: Levosimendan, a new inotropic and vasodilator agent. Anesthesiology; 104:556-69, 2006.

9. Perrone SV, Kaplinsky EJ: Calcium sensitizer agents: a new class of inotropic agents in the treatment of decompensated heart failure. Int J Cardiol; 103:248-55, 2005.

10. Hendren WG, Schreiber RS, Garretson LK. Extracorporeal bypass for the treatment of verapamil poisoning. Ann Emerg Med 1989;18:984-7.

11. Kenny J. Treating overdose with calcium channel blockers. BMJ 1994;308:992-3.

12. Durward A, Guerguerian AM, Lefebvre M, Shemie SD. Massive diltiazem overdose treated with extracorporeal membrane oxygenation. PediatrCrit Care Med 2003;4:372-6.

13. Ezidiegwu C, Spektor Z, Nasr MR, Kelly KC, Rosales LG. A case report on the role of plasma exchange in the management of a massive besylate intoxication. TherApher Dial 2008;12:1804.

14. Humbert VH Jr, Munn NJ, Hawkins RF. Noncardiogenic pulmonary edema complicating massive Diltiazem overdose. Chet 1991;99:258-9. 
15. Saravu K, Balasubramanian R. Near-Fatal poisoning. J Assoc Physicians India 2004;52:156-7.

16. Lam YM, Tse HF, Lau CP. Continuous calcium chloride infusion for massive nifedipine overdose. Chest 2001;119:1280-2.

\section{AUTHORS:}

1. B.R. Shivakumar

2. Hareesh R.

3. AkshayAgte

\section{PARTICULARS OF CONTRIBUTORS:}

1. Professor and Unit Head, Department of Medicine, Dr.B.R. Ambedkar Medical College and Hospital.

2. Assistant Professor, Department of Medicine, B.R. Ambedkar Medical College and Hospital.

3. Post Graduate, Department of Medicine, B.R. Ambedkar Medical College and Hospital.

\section{NAME ADDRESS EMAIL ID OF THE CORRESPONDING AUTHOR:}

Dr. Akshay Gajanan Agte, Department of Medicine, Dr. B.R. Ambedkar Medical College, Kadugodanahalli, Bangalore - 560045 .

Email-akshayagte@gmail.com

Date of Submission: 26/11/2013.

Date of Peer Review: 27/11/2013.

Date of Acceptance: 04/12/2013.

Date of Publishing: 12/12/2013 